\title{
THE HEALTH-CARE NEEDS AMONG OLDER PERSONS IN AN INDONESIAN URBAN SETTING
}

\author{
SETIAWAN E ${ }^{1,2 *}$, POEDJIBUDOJO JK ${ }^{3}$, TONDOK MS ${ }^{3}$ \\ ${ }^{1}$ Center for Medicines Information and Pharmaceutical Care, Faculty of Pharmacy, Universitas Surabaya, Surabaya, Indonesia. \\ ${ }^{2}$ Department of Clinical and Community Pharmacy, Faculty of Pharmacy, University of Surabaya, Surabaya, Indonesia. \\ ${ }^{3}$ Faculty of Psychology, University of Surabaya, Jl. Raya Kalirungkut, Surabaya, Indonesia.
}

Email: ekosetiawan.apt@gmail.com

Received: 06 March 2017, Revised and Accepted: 11 April 2017

\section{ABSTRACT}

Objective: The unmet health-care needs among older persons population should be identified and anticipated due to hideous potential impacts. Ironically, no published study regarding this phenomenon was found in Indonesia. Derived from the Indonesian population and civil data, this study was conducted to identify the health-care needs of urban older people living on Java Island, the most populated island in Indonesia.

Methods: A qualitative study was conducted in 3 subdistricts in Surabaya, the capital city of East Java, namely, Rungkut, Kenjeran, and Tenggilis. There were 9 focus group discussions (FGDs) conducted during March-August 2015. Participants in this study were recruited purposively, i.e., person in charge of "Karang Werda," and the discussion explored thematically various topics in the area of unmet health needs phenomena related to: (1) Availability, (2) accessibility, and (3) acceptability. A FGD guide was developed to ensure in-depth discussion.

Results: There were 90 older persons serving as volunteers who participated in this study. The unmet health-care needs addressed by participants in this study were (1) Integrated and specialized health-care services for older persons and (2) skillful yet age-friendly health-care personnel were needed by participants. Our findings pointed out that the unmet health-care needs in Indonesian urban settings were classified as primarily availability, accessibility, and acceptability issues.

Conclusion: The government needs to take actions to solve the challenges related to the fulfillment of health-care needs among older persons in Indonesia. Further study of the health care personnel's beliefs and attitudes in providing care among older persons needs to be conducted to provide a more holistic picture of the phenomena before making any strategy for the future Indonesia's health-care system.

Keywords: Older person, Health care, Unmet need, Palliative care, Availability, Accessibility.

(c) 2017 The Authors. Published by Innovare Academic Sciences Pvt Ltd. This is an open access article under the CC BY license (http://creativecommons. org/licenses/by/4. 0/) DOI: http://dx.doi.org/10.22159/ajpcr.2017.v10i7.18300

\section{INTRODUCTION}

Older people are an important component in a society [1-3]. Increasing number of older persons' population in the world needs government's serious attention to prepare a better health-care system that accommodates the needs of older persons, known as an age-friendly system [3]. However, there are some cases that the needs of older persons have been neglected or, even worst, been abused [4-6]. One of the most important needs at high risk to be neglected or abused among older persons is health-care needs. Published literature indicates that medical problems are commonly found along with the problems of unmet health-care needs among older persons [5,7-10]. Compared to younger adults, based on the differences in physical, psychological, and emotional conditions, health-care services for older people should be delivered in a manner that can fulfill the basic inner needs of this population.

The consequences of unmet health-care needs in any population, including older persons population, are ultimately dreadful [10-14]. Numerous studies reported that for those who are experiencing unmet health-care needs, the risk to be hospitalized is increased $[11,12,15]$. One study conducted by Long et al. emphasized the consequences of unmet health-care needs in terms of health-care utilization. In the study, there were $104(14.1 \%)$ and $85(11.5 \%)$ of 737 participants identified as patients with unmet health-care needs for doctor care and prescription drugs, respectively [11]. The percentage of patients who need health-care utilization, including outpatient care, emergency department (ER) visit, and hospital stay, were higher among those who were identified as patients with unmet needs compared to those with met health-care needs. The incremental health-care utilization will directly impact to the incremental cost.

The best effort to anticipate the unexpected consequences of unmet health-care needs is to identify what are the actual unmet healthcare needs in particular settings. Factors that contribute to the unmet health-care needs can be varied for different settings or geographical areas. However, in general, the factors that caused unmet healthcare needs among older persons will be classified into 3 main issues: (1) Availability, (2) accessibility, and (3) acceptability [16-20]. Factors related to the issue of availability include long waiting time for service(s) and services not available in the area where patient living at. Factors related to accessibility were cost and transportation. The acceptability issues include having a particular feeling such as being afraid of or dislike of health-care personnel and experiencing language barriers. One study conducted in France indicated that the main reason for unmet health-care needs among older people living was related to the availability issue [9]. Similar to that study, a study conducted by Ahn et al., in Korea found that the unmet needs of older people living in Korea were also related to the availability issue [20]. Knowing the main problems of unmet health-care needs among older persons will enable either the local or national governments to take actions effectively and efficiently.

However, the unmet health-care needs of older persons in Indonesia have not been identified yet. Health-care centers in Indonesia are classified as primary and secondary health care centers [21]. Primary health-care centers include Puskesmas (Pusat Kesehatan Masyarakat), clinics, and Private Physician Practice, while secondary health-care 
center refers to hospitals. Moreover, Indonesia has not only been classified as a country with one of the biggest population in the world but also as a country with a high proportion of older persons. It was estimated that there were approximately 20 million older people living in Indonesia or equal to $8.05 \%$ of all Indonesian population [22]. The absence of data regarding the unmet health-care needs among older persons in Indonesia may lead to an uninformed and inappropriate decision-making process that, finally, will lead to dissipation of the annual state budget without any significant impact to the society. Therefore, the aim of this study was to identify the health-care needs of older people living at municipalities in Indonesian urban setting.

\section{METHODS}

Qualitative approach was conducted using focus group discussion (FGD) to explore the community health-care needs of participants. Qualitative semistructured research questions were used in this study. The questions were initially listed to guide the participants while discussing particular research topics. Data obtained from this study could not be generalized for the national population. However, as an exploratory research, data derived from this study are important to highlight the older persons' needs and to give emphasis in a quantitative study.

\section{Study setting}

Java Island is the most populated island in Indonesia with approximately $57 \%$ of Indonesians living on this Island. There are 6 provinces located on Java Island and East Java is the second most populated province in Java Island, with approximately 39 million people. Moreover, East Java has been classified as the top of the three provinces with the highest proportion of older persons (10.96\%) [23]. In terms of health facilities, there are 229 and 960 public hospitals and Puskesmas in East Java Province, respectively [21]. There were 3,$785 ; 5,458 ; 15,406 ; 28,596$; 1,637 ; and 4,261 of medical specialists, general practitioners, midwives, nurses, pharmacists, and pharmacy technicians, respectively, in East Java Province [24].

Surabaya, the capital of East Java Province, is an urban area that consists of 30 subdistricts. As the capital of East Java Province and also as the second largest city in Indonesia, there are significant numbers of older people living in Surabaya. In 2014, approximately 7.25\% of Surabaya's citizens are older persons ( $>60$ years old), meaning that approximately 250,000 older persons live in Surabaya [25]. Meanwhile, there are only 5, 24, and 62 of public hospitals, private hospitals, and Puskesmas in Surabaya [21,24].

The Mayor of Surabaya has given good attention to the betterment of older persons' welfare by implementing several programs under the control of Provincial Sub-Project Management of Ministry of Social Services. One of the most promising programs implemented by Provincial Sub-Project Management of Ministry of Social Services is "Karang Werda."

\section{Study participants}

FGD were carried out in 3 subdistricts in Surabaya including: Rungkut, Tenggilis, and Kenjeran. A purposive sampling method was implemented in this study to listen to older persons' ideas who represent people with a grave concern of their community's health-care condition and the one who represent the needs of the majority of older people in the community. With this purpose, the Person in Charge of "Karang Werda" was included in the FGD. Those three sub-districts were chosen based on the profile of older persons living in each subdistrict. Most of the older persons living at Rungkut and Tenggilis are government staff retirees. Some of them are assigned as a board of Regional Commission of East Java Province. It was intended that involving them as participants will enable the researcher to hear the innermost health-care needs of older persons. Meanwhile, Kenjeran is a subdistrict located near the seashore. Most people living in that area are fishermen with low to intermediate income. Recruiting participants from that area will enable us to identify the problems experienced by the $11.30 \%$ of the population living below the national poverty lines.
FGD

FGDs were conducted from March to August 2015. To ensure that the interviews would be in an in-depth discussion, an interview guide was developed. It covered questions such as: (1) Please tell us about the challenges that you experience when you go to the health-care facilities and (2) please tell us about your expected health services at your regular visits to health-care center. There were 9 FGDs consisting of 8-11 older persons per group. The discussions were held at the village meeting hall of each subdistrict. Audio recording was not applicable for these discussions due to personal feelings of insecurity. Each discussion was facilitated by one facilitator and three assistants. The total number of facilitators and assistants involved in this study were 3 and 4 persons. Personal information sheets included age, marital status, ethnicity, job status, educational background, monthly income, health status (chronic and symptomatic health problem, medication history), and health-seeking behaviors (such as the frequency to check their health condition, the frequency of health-care center visits, nonmedication prescriptions they take, and their satisfaction of health-care services delivered).

\section{Ethical consideration}

Before the discussion, participants were informed about the objectives and benefits of the study. They were given information sheets and informed consent forms to complete as well as they were asked to fill in some personal information. Participants who were able to sign were required to sign the consent form before the FGD. However, for those who were unable to sign the form, the researcher asked for his/her thumbprint.

\section{Data management and analysis}

Data analysis was conducted during and after fieldwork by all researchers in this study. Coding was done by labeling ideas found in transcripts. One researcher (ES) provided a template to organize ideas found in transcripts. Coding results were managed manually and two of researchers (ES and mountain standard time) were responsible to manage the data. The thematic analysis approach was used to identify the health-care needs among participants. At the end, JKP led all researchers to the higher level of analysis by linking all the themes found in the study to the wider concepts.

\section{RESULT}

There were 9 groups consisting of 90 older persons who participated in the study and most of them were female $(60.00 \%)$, Javanese $(75.00 \%)$, and currently unemployed (70.00\%). Most of the participants $(45.00 \%)$ were graduated from senior high school. Moreover, $1.00 \%$ and $9.00 \%$ of participants were graduated from elementary and junior high school. One-third of the participants (35.00\%) were living with less than $\mathrm{Rp}$ 1 million per month (approximately USD \$75.00).

The analysis of participants' health status implied that $78.00 \%$ of the participants had chronic diseases, including diabetes mellitus, eye problems, gastrointestinal problems, heart problems, hypertension, hyperuricemia, and dyslipidemia. Moreover, approximately $40.00 \%$ of participants suffered from symptomatic health problems daily. Among all of the participants, $73.00 \%$ claimed taking 1-5 medicines per day while $6.00 \%$ of participants used 6-10 medicines per day.

The analysis of health-seeking behavior showed that one-third of participants did not make regular visits to health-care facilities to check their health status. The majority of respondents $(74.00 \%)$ were using medication without doctor prescription. Puskesmas, or the community health center at each municipality, was the most trusted health-care facility referred by participants in this study. There were approximately $25.00 \%$ participants who visit to Puskesmas regularly and felt unsatisfied with the health-care services provided at Puskesmas. Despite Puskesmas, other health-care facilities used by participants were public hospitals, private hospitals, "Posyandu lansia" (integrated health care services for the elderly), private physician office, private clinic, private midwife office, and "Mantri" (private nurse who 
provides health services). There were $56.67 \%$ of the participants who visit to public hospitals regularly and were unsatisfied with healthcare services provided at public hospitals. Almost a quarter of the participants in the study were not covered by health insurance, either public or private health insurance.

The following sections will present details of the participants' needs of health-care services.

Integrated and specialized health-care services for older persons Participants in the study pointed out that the fragmented health services implemented in Indonesia were considered as a burden by older persons, particularly those who had chronic diseases. For patients with complicated chronic health problems, they need to get some referral letter from a primary health care center to be able to receive services at a secondary health-care center. After the physician in the secondary health centers considered that the condition of a patient was quite stable, the patients were referred back to the primary health care to receive health services, including the medication. It was quite difficult for older persons to move between health-care centers not only because of their difficult health condition but also, most of them, still had responsibility to manage their household.

“...That was ok if they (the physicians at primary health care center) were reluctant to give us the medication. But they should not suggest us to go to hospital to take the medication... They had to consider how difficult for older person, like us, to move from one area to another area..." (male participant, 70 year-old from Rungkut subdistrict). (When giving this comment participant was showing an angry feeling).

"I did not know the reason why he (the physician at primary health care center) suggested me to go to the hospital... he said that there was something wrong with my blood pressure therefore I had to get services at the hospital... Now, after several time, the physician at hospital suggested me to get medication at Puskesmas again... It was so confusing for me." (male participant, 62 years old from Rungkut subdistrict). This statement was supported by other members of the group. Most of them nodded their head for some time in agreement acknowledging similar frustrations.

Not only the need of integrated health-care services for older persons, moreover, the participants in the present study also pointed out the need of having a health care center that provides services only for older persons. Getting services in the same health-care center with young adults would make them invest longer time to get the service. Somehow, sitting and waiting for longer time was extremely torturous.

"Sometimes, I felt no need to go to check my condition anymore because it was too far to go to the hospital from my house... Moreover, I had to wait for longer time because there were lots of people queuing at the hospital" (female participant, 60 years old from Kenjeran sub-district).

“...It (waiting for longer time) doesn't mean I was reluctant to do it... But, they (health care personnel) should be able to let older people to get service first not the younger one... They should understand that older persons like us had some health problems... I once felt so angry because I had to wait for long time while my knee was so painful..." (female participant, 65 years old from Tenggilis sub-district).

“...I understood... Totally understood that they (health care personnel) had no bad intentions to older people like us... I also understood that they were all so busy with all the patients ... but we just wanted them to put us as priority of the services ... How come they served younger person first just because they came before us ... We definitely couldn't beat them (younger patients) because they could do everything faster than us ..." (female participant, 62 years old from Kenjeran sub-district).
"What made me disappointed while sitting and waiting here was [remembering that I had not fulfilled] my responsibility at home... I should cook for my family, I should take care of my grandchildren, and so on... I'm just wondering why they (health care personnel) did not allocate particular hour only for us (older persons)" (female participant, 60 years old from Tenggilis sub-district).

\section{Skillful and age-friendly health-care personals}

This study found that most of participants appreciate not only how competent the health-care personnel were but also how kind and hospitable they were. Answering the probing question from facilitators regarding the most desirable health-care personnel, most of the members from all of the groups said similar statements including "hospitable and perceptive," "clever and competent," "examine carefully," "polite and humanist," "professional and indulgent," "communicative and persevering," "assertive," and "empathic." However, it was also noticed from several participants that they had an experience being served by unfriendly health-care personnel.

“...She (health care personnel at drug store) just gave me the medicine without any information given to me... actually, at least she should smile and said something to me..." (male participants, 65 years old from Kenjeran sub-district).

"After measuring my blood pressure, he (physician at Puskesmas) just gave me prescription... that's all... I did not mean it because I needed the medication to control my blood pressure, but... it would make me happy if he asked my feeling and condition that day" (female participants, 62 years old from Tenggilis sub-district).

Being served by unfriendly health-care personnel was really disappointing for older persons. They prefer to be served by not too brilliant health-care professionals but having a good attitude toward older persons. Moreover, the way health-care professionals treated them would determine their decision to move to other health-care facilities.

"Finally, I moved to another Puskesmas... I felt so happy with my new physician at the new Puskesmas because he treated me so kind..." (female participants, 62 years old from Kenjeran subdistrict).

"I would move to another health care center... but I am not quite sure that they (health care professionals at new health care center) would treat me better than the previous one..." (male participants, 71 years old from Rungkut sub-district).

\section{DISCUSSION}

This study, to our knowledge, was the first study identifying the health-care needs among older persons in Indonesian, particularly in a metropolitan city like Surabaya. Our findings showed that unmet health-care needs among older persons in Indonesia involve the issues of availability, accessibility, and acceptability of health-care services. Availability issue according to this study is related to the need of integrated and specialized health-care services for older persons. The need of integrated health services means that currently elderly patients still have to change the health center to get services when their health status changed. Actually, it was the bureaucracy made by the Indonesia's government in the era of new health care scheme, namely, Jaminan Kesehatan Nasional (JKN) that patients with health problems have to get health services first from a primary health center. If the physicians in the primary health center justify it is a complex or complicated health problem that primary health care is unable to handle, physicians have to refer the patients to a secondary health center. After patients are getting stable, physicians have to refer the patients back to a primary health center. It is not easy and quite expensive for older people to move from one health center to another health center. Some older people live quite far from secondary health center and they prefer to get services from a primary health center nearby their home. Indonesia Basic Health Research (2013) clearly emphasized that some people 
may take more than one type of transportation to go to a health center and it may take more than one hour and cost more than Rp. 50,000 (US\$ 4) to go to the health center [26]. It is clear that it would be very challenging for older people to move from one to another health center. In the circumstances with many difficulties in getting health services from health-care professionals, older people will try to seek other ways to overcome their health problems. Self-medication using overthe-counter and complementary medicines are commonly practiced by older persons to resolve their health problems. It has been reported that the prevalence of self-medication among older persons in one community setting in India was 38\% [27]. The most frequently used medicines in the study were vitamin and supplements. However, other publication revealed that the prevalence of self-medication in the elderly was as high as $87 \%$ and limited physical ability was found as a major contributor to the self-medication behavior among the elderly [28]. Pain killers, also known as analgesics, are one of the most frequently used medicines in self-medication practices among the elderly $[28,29]$ and it should be anticipated that one group of analgesic, namely, non-steroidal anti-inflammatory drugs, may increase the blood pressure among hypertensive patients [30]. It is worth noting that even though the medicines were prescribed by health professionals, several studies conducted in India emphasized that older people might still get inappropriate medication [31,32]. Mekonnen and Bhagavathula found that approximately $28 \%$ of 1252 older patients attending Gondar University Hospital were prescribed inappropriate medication [31]. A study conducted by Chowta et al. also found similar issue. There were $20.83 \%$ older patients attending geriatric clinic got medicine that was classified as inappropriate for elderly [32]. Consequently, the government has to ensure the availability of health services for every single citizen including older person to minimize the risk of older people to be treated with inappropriate medicines. Otherwise, the unavailability of older persons' desired health-care services will lead them to do irresponsible medication practices that may put them at the highest risk to get the worst clinical outcome.

It is also worthwhile to acknowledge that a quarter of the participants in this study had no insurance to cover their health expenses. This important finding could be considered as another aspect of the availability and accessibility issues among older persons in Indonesia's health-care system. Tavares et al. showed that having no health insurance coverage is one of the strongest determinant factors to the non-adherence behavior among older patients [33]. The adherence to medication is crucial behavior for most of older persons because they usually suffered from chronically degenerative disease(s). Being without health insurance coverage means that older patients have to pay themselves for visits to the doctor in cash also known as an out-ofpocket payment system. For people living with low-income per month below the poverty level, buying medication is extremely expensive because they have to spend extra money to be fitted with their basic necessities. In their study, Upadhyay and Joshi clearly stated that poor economic status was the dominant factor affecting the adherence behavior [27]. Moreover, for unemployed older person like $70.00 \%$ of the participants in this study, providing cash money for getting medication regularly is impossible to do. The government needs to take responsibility to provide coverage for the older people in the national health scheme. In 2014, Indonesia has started JKN program to cover health costs for all Indonesian citizens. This study calls for attention from the government staff to evaluate the methods of JKN socialization and the procedure for citizens' eligibility and accessibility, especially for older persons to get the insurance. Without any action being taken, having no health insurance will lead to greater burdens for national and local government.

Unavailability of required health services could have negative impact to older persons as individuals and also to the whole health-care system. More than $75 \%$ of older patients in the study had chronic disease(s) including diabetes mellitus and hypertension. Having chronic diseases has contributed to the more frequent access to health center [2]. One reason to visit a health center is to receive medication they need because they have to take the medication for the rest of their life. In most of older persons in the present study, 73.00\% used 1-5 medicines per day. Finding of the present study was similar with study conducted by Chowta et al. Majority of older patients in Chowta et al. used $<6$ medicines [32]. It has been proposed that being in adherence with the medication is one of the key components to control chronic diseases. The achievement of desired blood glucose target among diabetic patients $[34,35]$ and desired blood pressure target among hypertensive patients ultimately affects with the adherence to the medication [36]. Evidence showed that well-controlled blood pressure would decrease the risk of complications, such as heart diseases and stroke and mortality [37]. Unavailability of desired health services causes patients to be unsatisfied and reluctant to check their health status regularly. It is worth noting that one-third of participants in the present study did not come to health-care facilities to check their health status regularly. This behavior will put them in the highest risk to get complications. Solli et al. clearly emphasized that patients with complication(s) have lower quality of life compared with those without complications -[38]. Moreover, the burden of having complication(s) among patients with chronic diseases in the economic perspective is high. One study conducted by Wang et al. revealed that the health expenditure of patients with diabetic complication(s) is significantly higher than those without complications [39]. In a country that is implementing universal coverage payment system for health care, the government provides more funds to cope with higher health expenditure. Therefore, it is clearly shown that unmet needs of health services, finally, will decrease the individual patient's quality of life and increase the government's economic burden.

Another important finding of this study is the acceptability issue toward the health services perceived by older persons that may have negative impacts to the continuity of older patients' treatment. Participants in this study expressed that the attitude of health-care professionals was really disappointing to them. Most of participants in our study expected to be served with what they called as "skillful and age friendly health care personnel." Several studies revealed similar findings with ours. The first study was conducted in England by Potter [40]. Potter found 9 older persons' expectations toward health-care services, and 3 among those expectations indicated the same findings with ours including (1) opportunity to be listened to, (2) proactive healthcare, and (3) connected relationship between staff and patients. The second study done by Beverly et al. found that older patients in their study thought that health-care professionals showed unwillingness attitude and lack of communication while providing health services to older patients [41]. Inappropriate attitude of health-care professionals was proposed by Holt et al. as one of the significant contributing factors to the adherence profile among older persons particularly for women patients. It is clear that being treated inappropriately will lead older patients to stop visiting a health center either for getting medication or checking their health status [42].

The most important issue that should be addressed is whether it would be appropriate to blame health-care professionals because of the older persons' perception. Reader and Gillespie identified several factors contributing to the inappropriate attitude among health-care professionals while providing care to older persons and one of the most prominent factors was high workloads that make health-care professionals feel burnout [43]. In Indonesia, for example, the ratio between the numbers of physicians to total population is different from one province to others. According to data provided by Indonesia's Ministry of Health (2013), there were some provinces with not more than 12 physicians available for every 100,000 population [44] The number of physicians working in rural or remote area is even lower compared to cities. Given these considerations, it is obviously shown that physicians cannot deliver quality of care as expected by older persons.

In general, health care professionals should provide a care for every single patient, including older persons, appropriately. However, in 
some cases, health-care professionals may provide a care with negative emotions. For example, a study conducted by Samra et al. clearly stated that health-care professionals, in this case it was physicians, had negative feeling when they were treating older patients [45]. That feeling was not caused by the behavior or attitude of older patients, but it was more related with being afraid to fail in treating older patients and being dissatisfied with the aging unfriendly health system [45]. Beliefs and attitude of health care professionals in providing care to older patients in Indonesia have not been properly explored yet. Therefore, there should be a diminished tendency to blame physicians regarding the perception of older patients toward the attitude of health-care professionals. Further research investigating the attitude and belief among Indonesia's health-care professionals is ultimately needed to get better understanding about the problems and difficulties in providing care for older patients.

\section{CONCLUSION}

In conclusion, the availability, accessibility, and acceptability issues of health services perceived by older persons have to be taken into consideration by the government in future strategic planning for Indonesia's health system. Older people expect to receive a holistic care in non-fragmented health centers and to be served by competent yet age-friendly health care professionals. There is a great tendency for older people to avoid visiting a health center regularly either for checking their health status or getting medication if the availability, accessibility, and acceptability issues perceived by older person have not been fixed yet. On the other hand, it is extremely difficult for physicians to provide a friendly holistic professional care for every single older person because of high workloads. Support from the local and central government is ultimately needed to overcome the issues. The government should consider to increase the number of physicians, to distribute physicians to all regions equally, and to conduct a socialization session for a JKN program exclusively for older person.

\section{Disclaimer}

We would like to give appreciation for funding given by Indonesian Directorate General of Higher Education (DIKTI), Ministry of Education, Indonesia, for the "Hibah Penelitian Fundamental" grant scheme.

\section{REFERENCES}

1. Zammit AR, Starr JM, Johnson W, Deary IJ. Profiles of physical, emotional and psychosocial wellbeing in the Lothian birth cohort 1936. BMC Geriatr 2012;12:64.

2. Wandera SO, Kwagala B, Ntozi J. Determinants of access to healthcare by older persons in Uganda: A cross-sectional study. Int J Equity Health 2015;14:26.

3. World Health Organization. Global Health and Aging. Geneva: World Health Organization; 2013

4. Naughton C, Drennan J, Treacy MP, Lafferty A, Lyons I, Phelan A, et al. Abuse and Neglect of Older People in Ireland: Report on the National Study of Elder Abuse and Neglect. Dublin: National Centre for the Protection of Older People; 2010.

5. Kshetri DB, Smith WC. Self-reported health problems, health care utilisation and unmet health care needs of elderly men and women in an urban municipality and a rural area of Bhaktapur district of Nepal. Aging Male 2011;14(2):127-31.

6. Dziechciaz M, Guty E, Wojtowicz A, Filip R. Social and health care needs of elderly people living in the countryside in Poland. Ann Agric Environ Med 2012;19(4):746-50.

7. Lena A, Ashok K, Padma M, Kamath V, Kamath A. Health and social problems of the elderly: A cross-sectional study in Udupi taluk, Karnataka. Indian J Community Med 2009;34(2):131-4

8. Thakur R, Banerjee A, Nikumb V. Health problems among the elderly: A cross-sectional study. Ann Med Health Sci Res 2013;3(1):19-25.

9. Herr M, Arvieu JJ, Aegerter P, Robine JM, Ankri J. Unmet health care needs of older people: Prevalence and predictors in a French crosssectional survey. Eur J Public Health 2014;24(5):808-13.

10. Gauld R, Raymont A, Bagshaw PF, Nicholls MG, Frampton CM. The importance of measuring unmet healthcare needs. N Z Med J 2014:127(1014):63-7.
11. Long SK, King J, Coughlin TA. The implications of unmet need for future health care use: Findings for a sample of disabled Medicaid beneficiaries in New York. Inquiry 2005;42(4):413-20.

12. Quail JM, Wolfson C, Lippman A. Unmet need and psychological distress predict emergency department visits in community-dwelling elderly women: A prospective cohort study. BMC Geriatr 2011;11:86.

13. Puts MT, Papoutsis A, Springall E, Tourangeau AE. A systematic review of unmet needs of newly diagnosed older cancer patients undergoing active cancer treatment. Support Care Cancer 2012;20(7):1377-94.

14. Yamada T, Chen CC, Murata C, Hirai H, Ojima T, Kondo K, et al. Access disparity and health inequality of the elderly: Unmet needs and delayed healthcare. Int J Environ Res Public Health 2015;12(2):1745-72.

15. Gruneir A, Silver MJ, Rochon PA. Emergency department use by older adults: A literature review on trends, appropriateness, and consequences of unmet health care needs. Med Care Res Rev 2011;68(2):131-55.

16. Chen J, Hou F. Unmet needs for health care. Health Rep 2002;13(2):23-34

17. Sanmartin C, Houle C, Tremblay S, Berthelot JM. Changes in unmet health care needs. Health Rep 2002;13(3):15-21.

18. Nelson $\mathrm{CH}$, Park J. The nature and correlates of unmet health care needs in Ontario, Canada. Soc Sci Med 2006;62(9):2291-300.

19. Pappa E, Kontodimopoulos N, Papadopoulos A, Tountas Y, Niakas D. Investigating unmet health needs in primary health care services in a representative sample of the Greek population. Int J Environ Res Public Health 2013;10(5):2017-27.

20. Ahn YH, Kim NH, Kim CB, Ham OK. Factors affecting unmet healthcare needs of older people in Korea. Int Nurs Rev 2013;60(4):510-9.

21. Badan Pusat Statistik East Java Province. Banyaknya Rumah Sakit Umum, Puskesmas dan Puskesmas Pembantu 2010-2013; 2015. Available from: http://www.jatim.bps.go.id/linktablestatis/view/id/309. [Last cited on 2016 Apr 20].

22. The World Bank. Population Ranking; 2015. Available from: http:// www.data.worldbank.org/data-catalog/Population-ranking-table. [Last cited on 2016 Apr 20].

23. Badan Pusat Statistik East Java Province. Profil Penduduk Lanjut Usia Jawa Timur 2014. Surabaya: Badan Pusat Statistik Jawa Timur; 2014.

24. Provincial Office of Ministry of Health. Profil Kesehatan Provinsi Jawa Timur Tahun 2012. Surabaya: Dinas Kesehatan Provinsi Jawa Timur; 2012.

25. Badan Pusat Statistik Surabaya. Banyaknya Penduduk Menurut Jenis Kelamin Per Kecamatan Hasil Registrasi, 2014; 2015. Available from: http://www.surabayakota.bps.go.id/webbeta/frontend/linkTableStatis/ view/id/322. [Last cited on 2016 Apr 20]

26. Kementerian Kesehatan Republik Indonesia (Kemenkes RI). Riset Kesehatan Dasar (RISKESDAS) 2013; 2013. Available from: http://www.depkes.go.id/resources/download/general/Hasil\%20 Riskesdas\%202013.pdf. [Last cited on 2016 Apr 20].

27. Upadhyay J, Joshi Y. Observation of drug utilization pattern and prevalence of diseases in elderly patients through home medication review. Asian J Pharm Clin Res 2011;4(1):143-5.

28. Jerez-Roig J, Medeiros LF, Silva VA, Bezerra CL, Cavalcante LA, Piuvezam G, et al. Prevalence of self-medication and associated factors in an elderly population: A systematic review. Drugs Aging 2014;31(12):883-96.

29. Goh LY, Vitry AI, Semple SJ, Esterman A, Luszcz MA. Self-medication with over-the-counter drugs and complementary medications in South Australia's elderly population. BMC Complement Altern Med 2009:9:42

30. Zheng L, Du X. Non-steroidal anti-inflammatory drugs and hypertension. Cell Biochem Biophys 2014;69(2):209-11.

31. Mekonnen AB, Bhagavathula AS. Inappropriate medication use in the elderly population attending Gondar University Hospital: A preliminary assessment. Int J Pharm Pharm Sci 2014;6(10):540-3.

32. Chowta MN, Adhikari PM, Raj S, Laxman M, Kariappa A, George J, et al. Evaluation of appropriateness of prescription and polypharmacy in the geriatric population: A cross-sectional study at a comprehensive geriatric clinic in a tertiary care hospital. Int J Pharm Pharm Sci 2016;8(3):119-23

33. Tavares NU, Bertoldi AD, Thumé E, Facchini LA, França GV, Mengue SS. Factors associated with low adherence to medication in older adults. Rev Saude Publica 2013;47(6):1092-101.

34. Aikens JE, Piette JD. Longitudinal association between medication adherence and glycaemic control in Type 2 diabetes. Diabet Med 2013;30(3):338-44.

35. Nagrebetsky A, Griffin S, Kinmonth AL, Sutton S, Craven A, Farmer A. Predictors of suboptimal glycaemic control in Type 2 diabetes patients: The role of medication adherence and body mass index in 
the relationship between glycaemia and age. Diabetes Res Clin Pract 2012;96(2):119-28

36. Matsumura K, Arima H, Tominaga M, Ohtsubo T, Sasaguri T, Fujii $\mathrm{K}$, et al. Impact of antihypertensive medication adherence on blood pressure control in hypertension: The COMFORT study. QJM 2013;106(10):909-14.

37. Emdin CA, Rahimi K, Neal B, Callender T, Perkovic V, Patel A. Blood pressure lowering in Type 2 diabetes: A systematic review and metaanalysis. JAMA 2015;313(6):603-15

38. Solli O, Stavem K, Kristiansen IS. Health-related quality of life in diabetes: The associations of complications with EQ-5D scores. Health Qual Life Outcomes 2010;8:18.

39. Wang W, Fu CW, Pan CY, Chen W, Zhan S, Luan R, et al. How do Type 2 diabetes mellitus-related chronic complications impact direct medical cost in four major cities of urban China? Value Health 2009;12(6):923-9.

40. Potter C. What quality healthcare means to older people: Exploring and meeting their needs. Nurs Times 2009;105(49-50):14-8

41. Beverly EA, Wray LA, Chiu CJ, LaCoe CL. Older adults' perceived challenges with health care providers treating their Type 2 diabetes and comorbid conditions. Clin Diabetes 2014;32(1):12-7.

42. Holt E, Joyce C, Dornelles A, Morisky D, Webber LS, Muntner P, et al. Sex differences in barriers to antihypertensive medication adherence: Findings from the cohort study of medication adherence among older adults. J Am Geriatr Soc 2013;61(4):558-64.

43. Reader TW, Gillespie A. Patient neglect in healthcare institutions: A systematic review and conceptual model. BMC Health Serv Res 2013;13:156.

44. Ministry of Health Republic of Indonesia. Indonesia Health Profile 2013. Jakarta: Ministry of Health Republic of Indonesia; 2014.

45. Samra R, Griffiths A, Cox T, Conroy S, Gordon A, Gladman JR. Medical students' and doctors' attitudes towards older patients and their care in hospital settings: A conceptualisation. Age Ageing 2015;44(5):776-83. 